\title{
Implementasi Metode Prototype dalam Membangun Sistem Informasi Penjualan Online pada Toko Herbal Pahlawan
}

\author{
Achmad Zuhri Al Muhtadi ${ }^{1}$, Lukman Junaedi' ${ }^{2)}$ \\ Sistem Informasi, Fakultas Ilmu Komputer, Universitas Narotama Surabaya, \\ J1. Arif Rahman Hakim No.51, Surabaya, 60117, Indonesia \\ azuhri150@gmail.com
}

\begin{abstract}
Abstrak
Berkembangnya media informasi pada era teknologi saat ini, era digital mempunyai peran penting dalam menunjang aktivitas. Salah satu perilaku yang menjadi trend pada kalangan masyarakat saat ini adalah belanja online melalui E-Commerce, sehingga menjadikan E-Commerce sebagai sarana untuk mempermudah transaksi jual beli dari segi tenaga, biaya, dan waktu yang telah ditentukan. Tujuan dari penelitian ini adalah untuk membangun sistem informasi penjualan secara online pada Toko Herbal Pahlawan supaya memperluas jangkuan pemasaran produknya. Metode yang digunakan dalam penelitian ini adalah prototype dan dirancang menggunakan unified modelling language (UML) dan aplikasi pencil versi 3.0.4 sebagai desain interface. Pembuatan website menggunakan pemrograman Hypertext Preprocessor (PHP), Framework Codeigniter dan MySql sebagai database untuk penyimpanan data. Hasil pengujian sistem tersebut menggunakan metode blackbox. Output dari penelitian ini adalah aplikasi penjualan online berbasis website pada Toko Herbal Pahlawan yang menyediakan fitur stok barang, laporan stok barang, laporan penjualan, melakukan transaksi, mengelola data produk.
\end{abstract}

Kata kunci: E-Commerce, Prototype, UML, MySql, Codeigniter

\section{Pendahuluan (Introduction)}

Maraknya media informasi pada era teknologi saat ini, era digital mempunyai peran penting dalam menunjang aktivitas. Teknologi informasi mampu memberikan efektifitas dan keakuratan yang dapat mengorganisir data perusahaan baik dalam jumlah besar serta membantu perusahaan dalam mengambil keputusan dan strategi didalam kebijakan perusahaan (Indrayani, 2012). Sistem informasi saat ini dapat memberikan kontribusi terhadap kebutuhan perusahaan untuk membangun suatu keunggulan yang kompetitif. Salah satunya bisnis yang menjadi trend pada kalangan masyarakat saat ini adalah belanja online atau E-Commerce. Trend ini akan memberikan kemudahan hingga menjadikan E-Commerce sebagai cara perdagangan yang lebih mempermudah dari segi tenaga, biaya dan waktu yang telah ditentukan. Hal ini dapat kita dilihat dengan persaingan yang semakin ketat di tiap-tiap perusahaan berusaha meningkatkan kualitasnya agar dapat memenuhi kebutuhan untuk bersaing di dunia bisnis serta demi tercapainya tujuan perusahaan.

Toko Herbal Pahlawan adalah sebuah toko yang bergerak dalam bidang penjualan dan jasa kesehatan yang melayani penjualan obat-obatan herbal. Transaksi yang digunakan oleh Toko Herbal Pahlawan menggunakan sistem penjualam secara offline dan pembayaranya dilakukan secara tunai. Selain itu Toko Herbal Pahlawan belum berkembang dalam mengelola toko sehingga Branding kurang dilakukan untuk memperluas jangkauan pemasaran. Toko Herbal Pahlawan sudah menerapkan Visual Branding dengan cara membuat Logo toko, namun Toko Herbal Pahlawan belum melakukan Digital Branding. Salah satu Branding Digital yang paling umum dilakukan adalah menggunakan Website. Selain sebagai media dalam melakukan Branding, website juga bisa digunakan sebagai sarana dalam melakukan pemasaran produk (Rahmadhani, 2017). 
Dalam kasus ini Owner atau pemilik toko memiliki kebutuhan akan sebuah sistem yang dapat digunakan untuk memasarkan produknya, akan tetapi mempunyai keterbatasan yang tidak dimilikinya seperti sistem informasi untuk membantu penjualan Toko Herbal Pahlawan dalam melakukan penjulan obat-obatan herbal.

Hal ini perlu dibuat sebuah acuan dari sistem yang akan dibangun. Penulis akan membangun sebuah sistem informasi penjualan dengan metode prototype. Metode prototype diharapkan dapat memudahkan pengguna dalam memilih sistem yang sesuai dari apa yang telah diharapkan oleh pengguna.

Untuk mendukung penelitian telah dianalisa beberapa penelitian yang berkaitan dengan penelitian ini, yaitu:

1. Penelitian dari Hidayat, Marlina and Utami (2017) pada Jurnal Simnasiptek yang berjudul "Perancangan sistem informasi penjualan barang handmade berbasis website dengan metode waterfall". Penelitian ini memiliki persamaan dalam hal penjualan namun terdapat perbedaan pada metode yang digunakan yaitu menggunakan waterfall. Hasil yang didapatkan pada output penelitian ini adalah adanya sistem penjualan barang handmade berupa website yang bertujuan untuk mengurangi biaya pemasaran produk.

2. Penelitian dari Rahmawati and Mulyono (2016) pada Jurnal Manajemen Sistem Informasi 2016 yang berjudul "Analisa dan perancangan sistem informasi pemasaran berbasis web pada Toko Billy". Penelitian ini mempunyai persamaan dalam metode yang digunakan yaitu menggunakan metode Prototype, namun memiliki perbedaan pada sistem yang dibuat yaitu sistem pemasaran. Hasil yang didapat pada penelitian ini adalah output website untuk mengolah sistem pemasaran pada toko billy yang mempermudah dalam penyimpanan data dengan memanfaatkan sistem teknologi informasi.

3. Penelitian dari Susanti (2016) pada Jurnal Informatika yang berjudul "Perancangan Sistem Informasi Akademik berbasis web pada SMK Pasar Minggu Jakarta". Penelitian ini memiliki persamaan pada sistem yang berbasis website, namun berbeda pada metode yang digunakan yaitu waterfall. Hasil penelitian yang didapatkan yaitu output website yang mempermudah siswa dan orangtua dalam mengakses informasi tanpa harus datang ke sekolah.

\section{2. $\quad$ Metode Penelitian (Methods)}

Pada penelitian ini meggunakan metode Prototype dikarenakan mempunyai fungsi sebagai versi awal dari sistem. Metode Prototype akan menghasilkan sistem sebagai perantara antara Developer dan User karena dapat memudahkan User dalam memilih sistem yang sesuai dari apa yang diharapkan Pembuatan model software yang sederhana dengan penggambaran dasar yang digunakan untuk dijadikan rancangan merupakan pengertian dari prototype (Priyambudi, 2017). Metodologi prototype ada empat, yaitu :

1. Illustrative

Memberikan output contoh laporan dan tampilan layer

2. Simulated

Menampilkan simulasi alur sistem tetapi tidak menggunakan data yang nyata.

3. Functional

Menampilkan simulasi alur sistem tetapi dengan menggunakan data yang nyata.

4. Evolutionary

Memberikan output yang telah dijadikan output bagian dari operasional sistem.

\subsection{Workshop Prototype}

Tujuan menggunakan metode prototype adalah megumpulkan data informasi dari pengguna sehingga pembuatan sistem dapat memperhatikan keluhan pada pengguna. Pembangunan sistem 
informasi ini meliputi yaitu perancangan proses prototype, perancangan basis data (database) dan antarmuka (desain interface). Adapun Tahapan dalam proses Prototyping yang telah digambarkan pada Gambar 1, meliputi Pengumpulan Kebutuhan, Membangun Prototyping, Evaluasi Prototyping, Mengkodekan Sistem, Menguji Sistem, Evaluasi Sistem, Penggunaan Sistem.

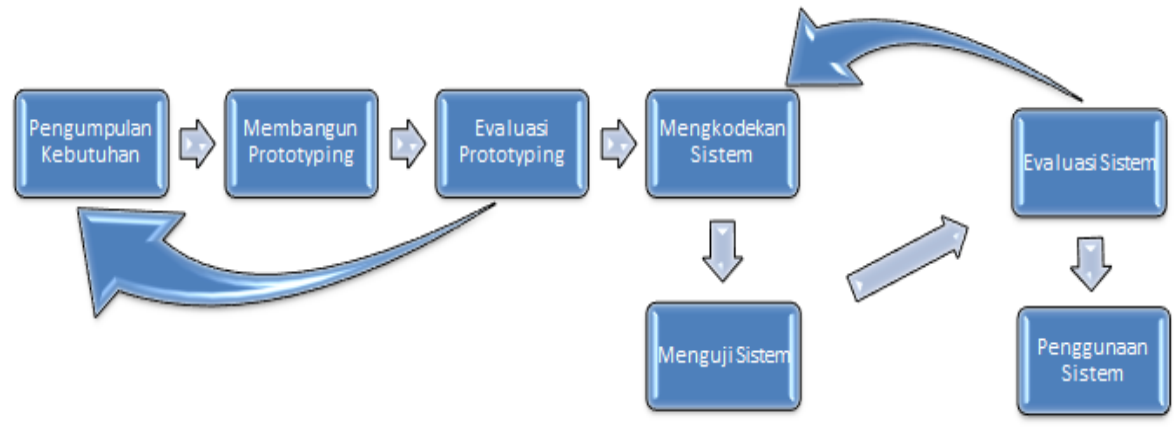

\subsection{Konsep dasar penjualan.}

\section{Gambar 1. Alur Prototype}

Penjualan merupakan suatu kegiatan terpadu yang bertujuan untuk pengembangan usaha dan memenuhi kebutuhan konsumen, memperoleh laba dan sebagai pemuas kebutuhan. Penjualan dalam sistem informasi meliliki prosedur meliputi diterima pesanan dari pembeli, pengecekan barang, pengadaan faktur, pencatatan, dan penjualan (Kristanto, 2018).

\section{Hasil dan Pembahasan (Results and Discussions)}

Dalam melakukan pengembangan sistem saat ini dibutuhkan sebuah analisis dan desain sistem atau perancangan untuk dapat mengelola data penjualan dengan tepat, cepat, dan benar. Sedangkan dalam perancangan atau desain sistem merupakan bagian yang harus ditempuh untuk menyajikan sistem agar dapat berjalan atau terorganisir dengan baik dan benar.

\subsection{Analisis Kebutuhan}

Pada analisis sistem di Herbal Pahlawan ada tiga tahap yang terdiri dari survei, permasalahan, pemecahan masalah.

\subsubsection{Survei}

Survei dilakukan di Toko Herbal Pahlawan yang dimana peneliti meminta informasi mengenai prosedur penjualan dan pencatatan laporan, survei juga meliputi penelitian terhadap kondisi cara transaksi yang dilakukan oleh pemilik toko dalam melayani pelanggannya di Toko Herbal Pahlawan.

\subsubsection{Permasalahan yang dihadapi Toko Herbal Pahlawan}

Dalam melakukan penjualan Herbal Pahlawan masih secara offline dan dari segi pencatatan laporan Herbal Pahlawan masih menggunakan cara yang lama yaitu sistem pencatatan melalui buku yang dimana buku tersebut dapat hilang atau terjadi hal-hal lainnya yang tidak diinginkan.

\subsubsection{Pemacahan Masalah}

Dengan permasalahan yang ada dapat di selesaikan atau diatasi dengan pembuatan sistem informasi penjualan. Jadi setiap ada pesanan yang masuk, dan laporan penjualan setelah melakukan transaksi dapat tercatat otomatis di database. 


\subsection{Perancangan Sistem Menggunakan UML (Unified Modeling Language)}

Dalam pengerjaan pembangunan Sistem Informasi penjualan online pada Toko Herbal Pahlawan kita perlu merancang suatu sistem dengan membentuk arsitektur dengan memakai UML (Unified Modeling Language). Unified ModelingLanguage (UML) bukanlah merupakan bahasa pemprograman tetapi modelmodel yang tercipta berhubungan langsung dengan berbagai macam bahasa pemprograman, sehingga memungkinkan melakukan pemetaan (mapping) langsung dari model-model yang dibuat dengan Unified Modeling Language (UML) dengan bahasa Pemrograman berorientasi objek (Dharwiyanti and Wahono, 2003).

\subsubsection{Usecase Diagram}

Usecase Diagram merupakan gambaran interaksi antara sistem dengan sistem pengguna (Pengetahuan and Komputer, 2018).

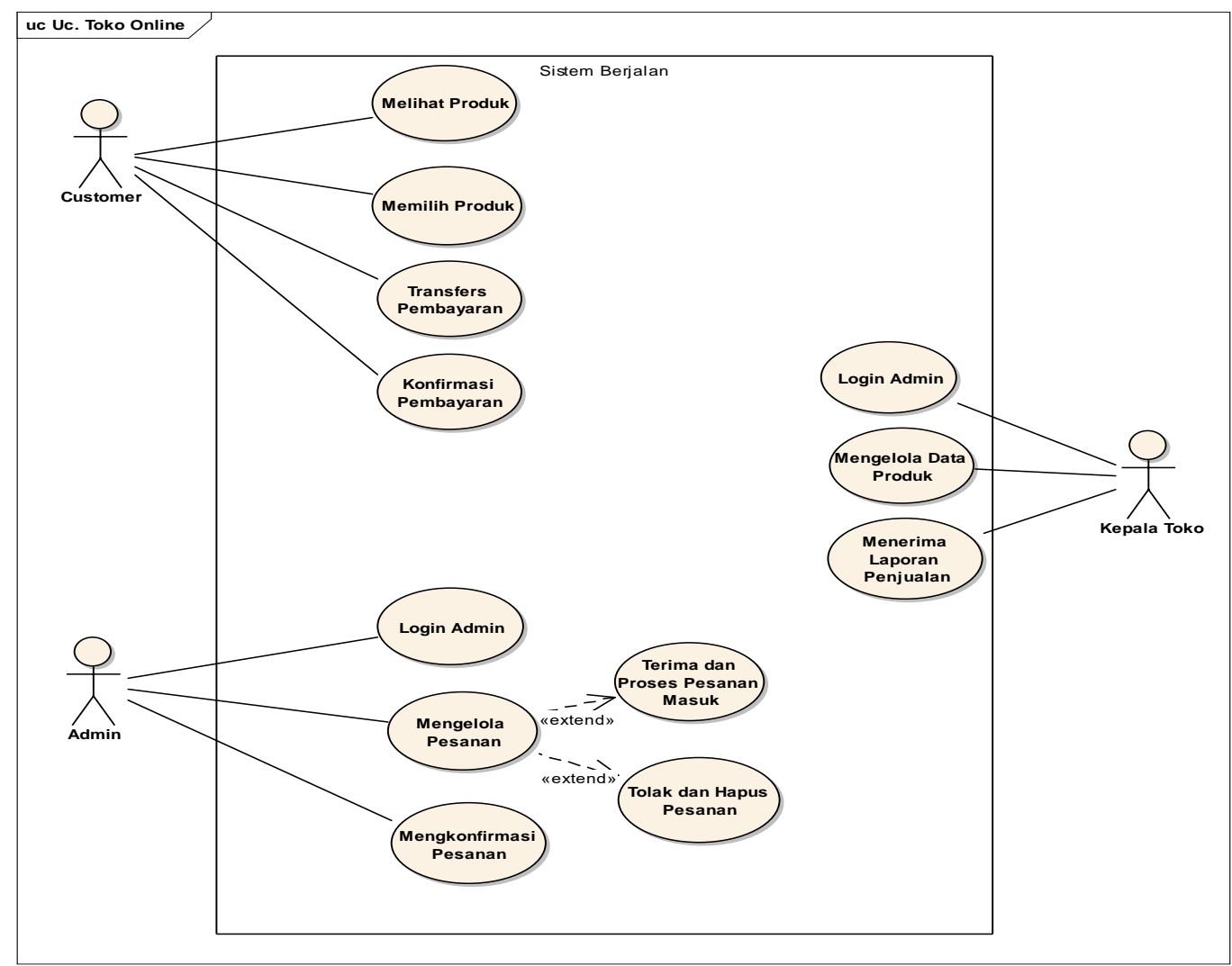

\subsubsection{Activity Diagram}

Gambar 2. Usecase Diagram

Activity Diagram merupakan gambaran workflow (aliran kerja) atau penggambaran aktivitas sistem proses bisnis (Hendini, 2016). Adapun Activity Diagram Login Admin dan Pemesanan dan Pembayaran dalam penjualan online pada Toko Herbal Pahlawan sebagai berikut: 


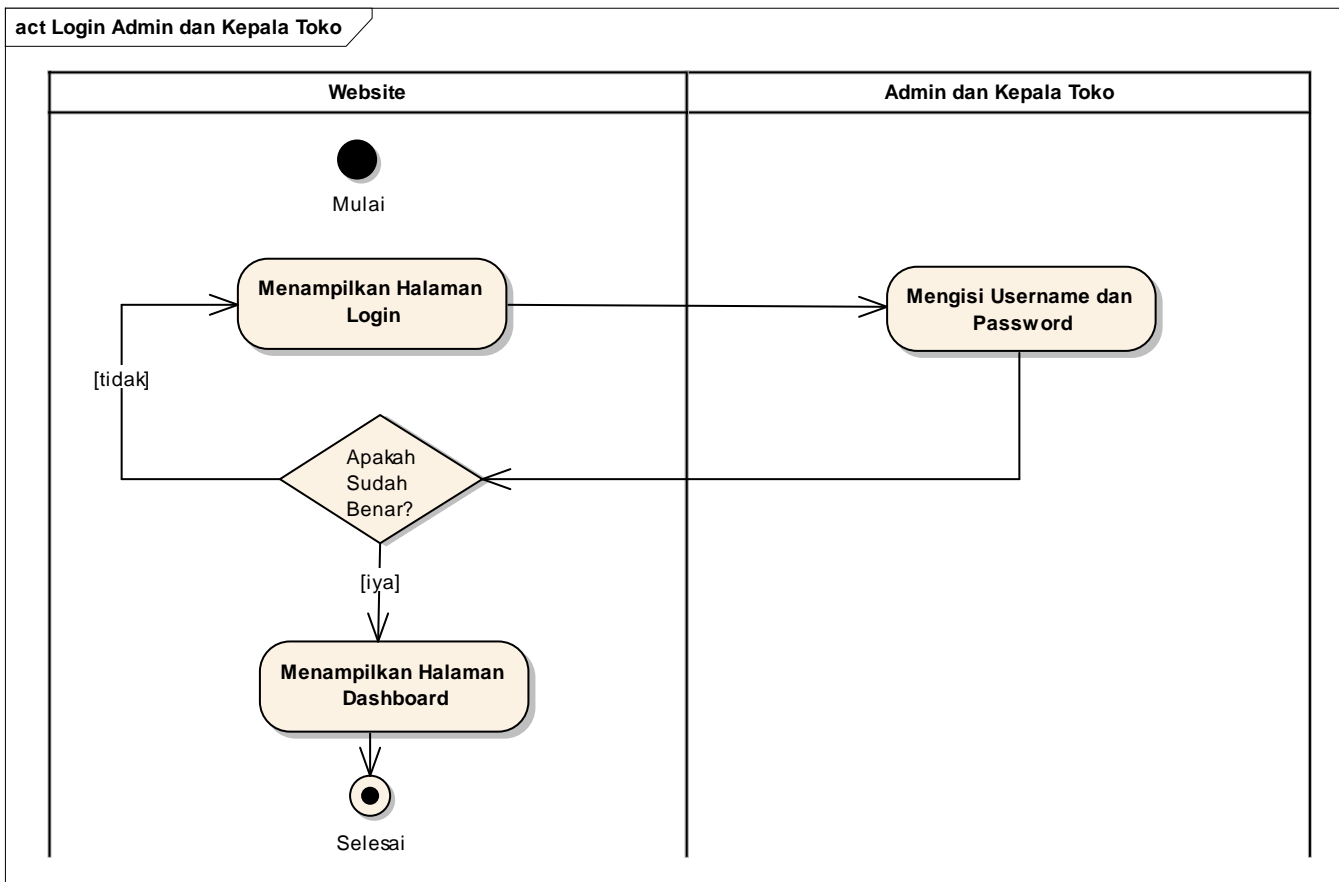

Gambar 3. Activity Diagram pada Halaman Login Admin

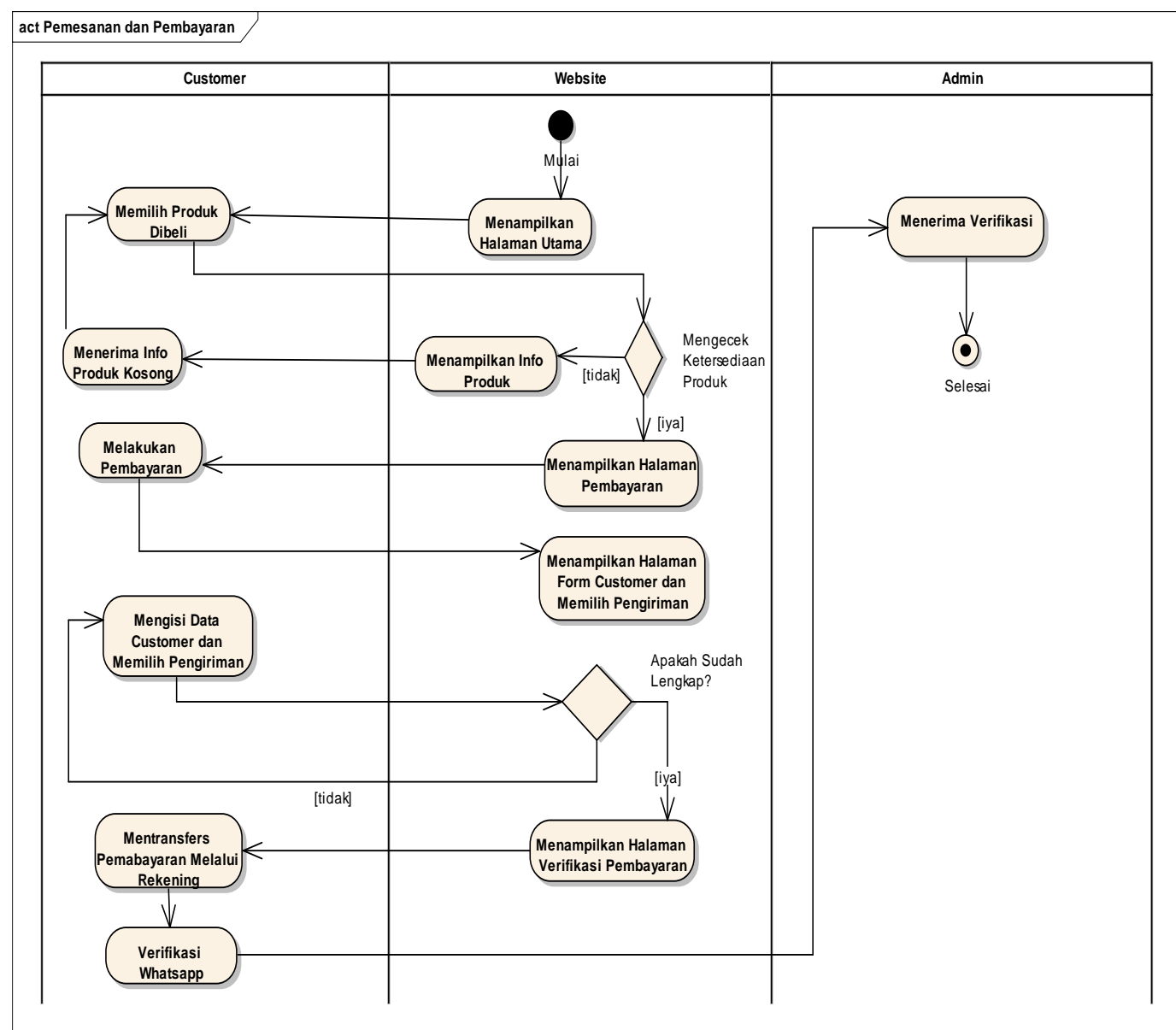

Gambar 4. Activity Diagram Pemesanan dan Pembayaran

\subsubsection{Sequence Diagram}

Sequence Diagram merupakan gambaran interaksi yang terjadi antar objek di dalam maupun disekitar sistem, berupa pesan yang digambarkan (Hendini, 2016). Adapun Sequence Diagram dalam penjualan online pada Toko Herbal Pahlawan sebagai berikut: 


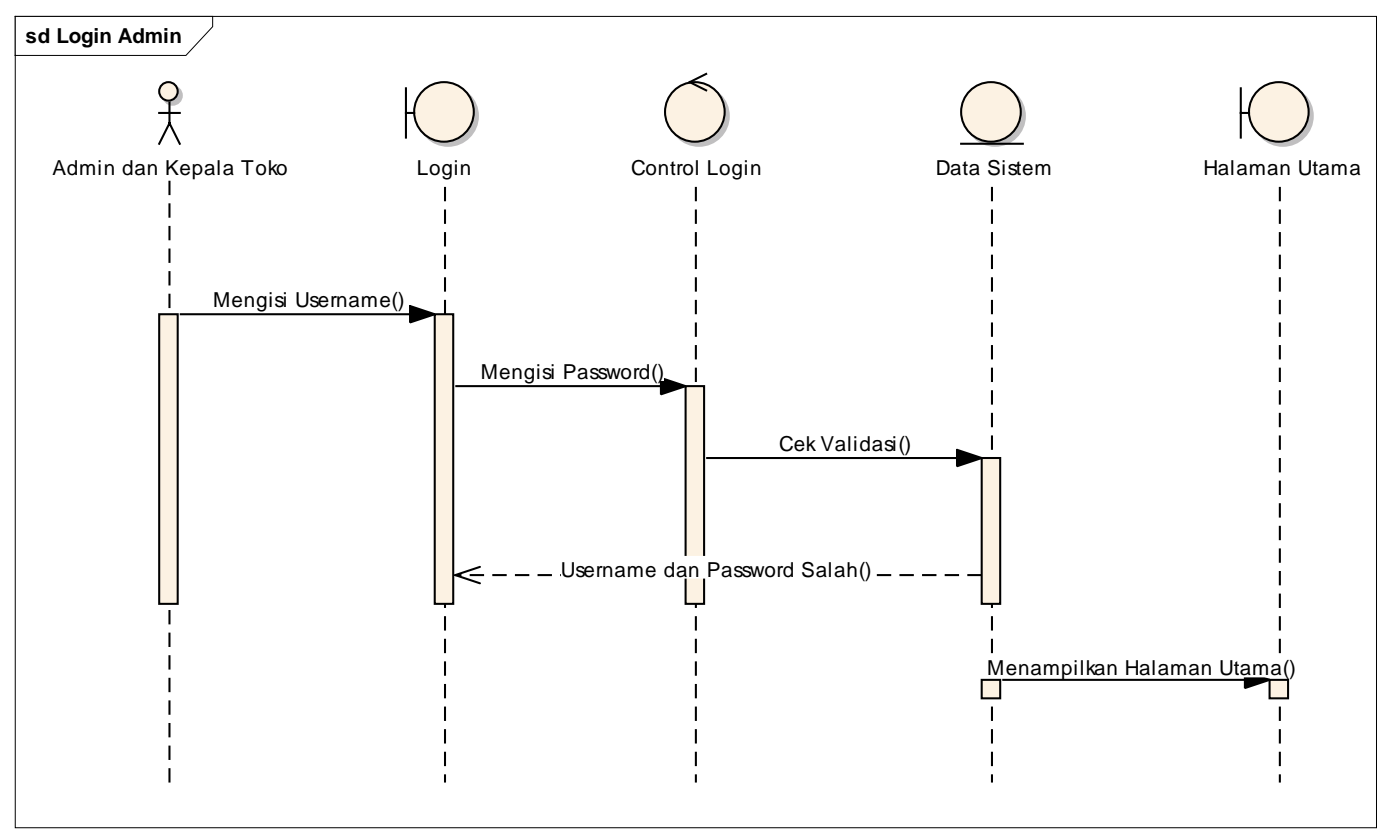

Gambar 5. Sequence Diagram Login Admin

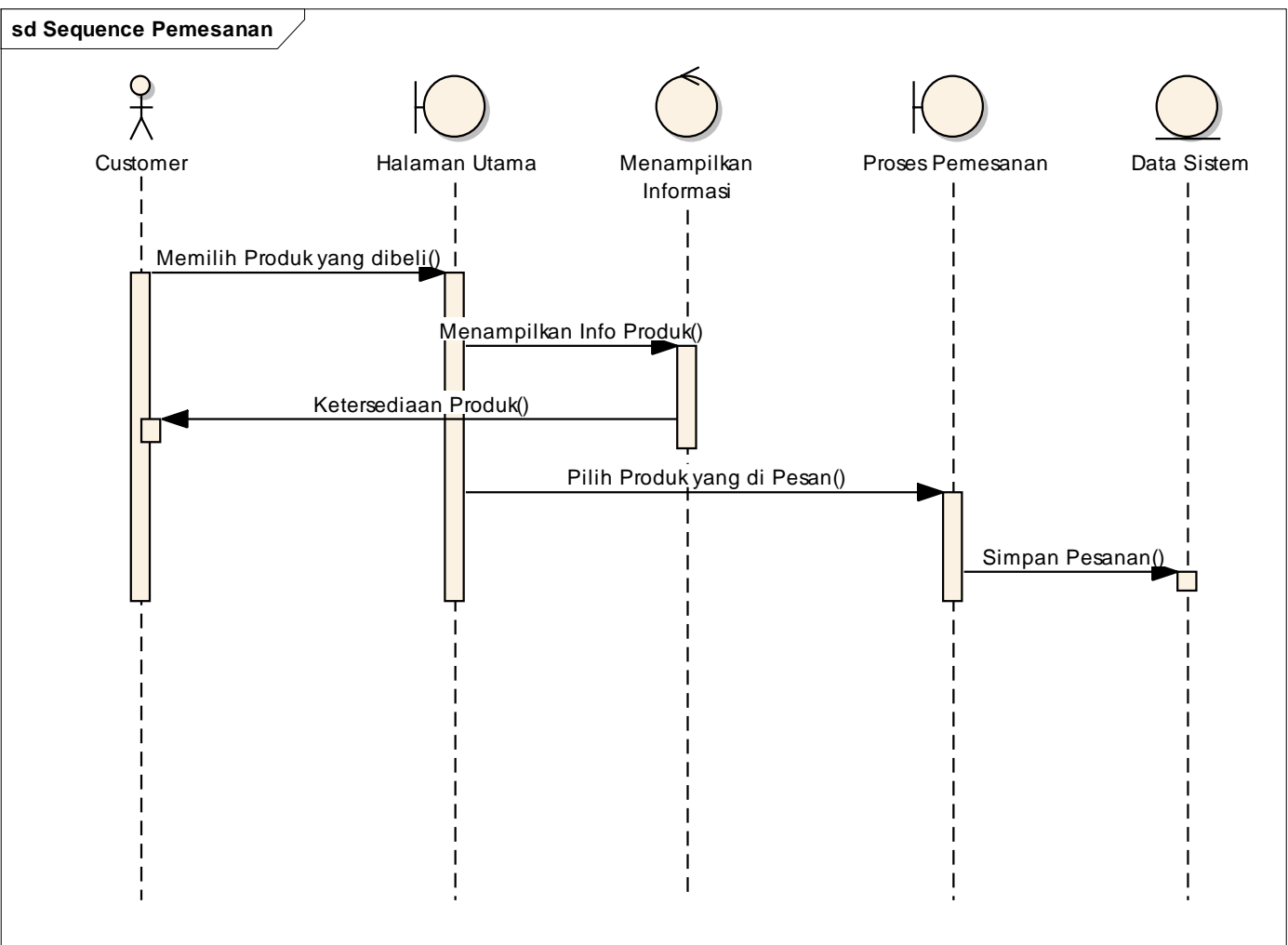

Gambar 6. Sequence Diagram Pemesanan 


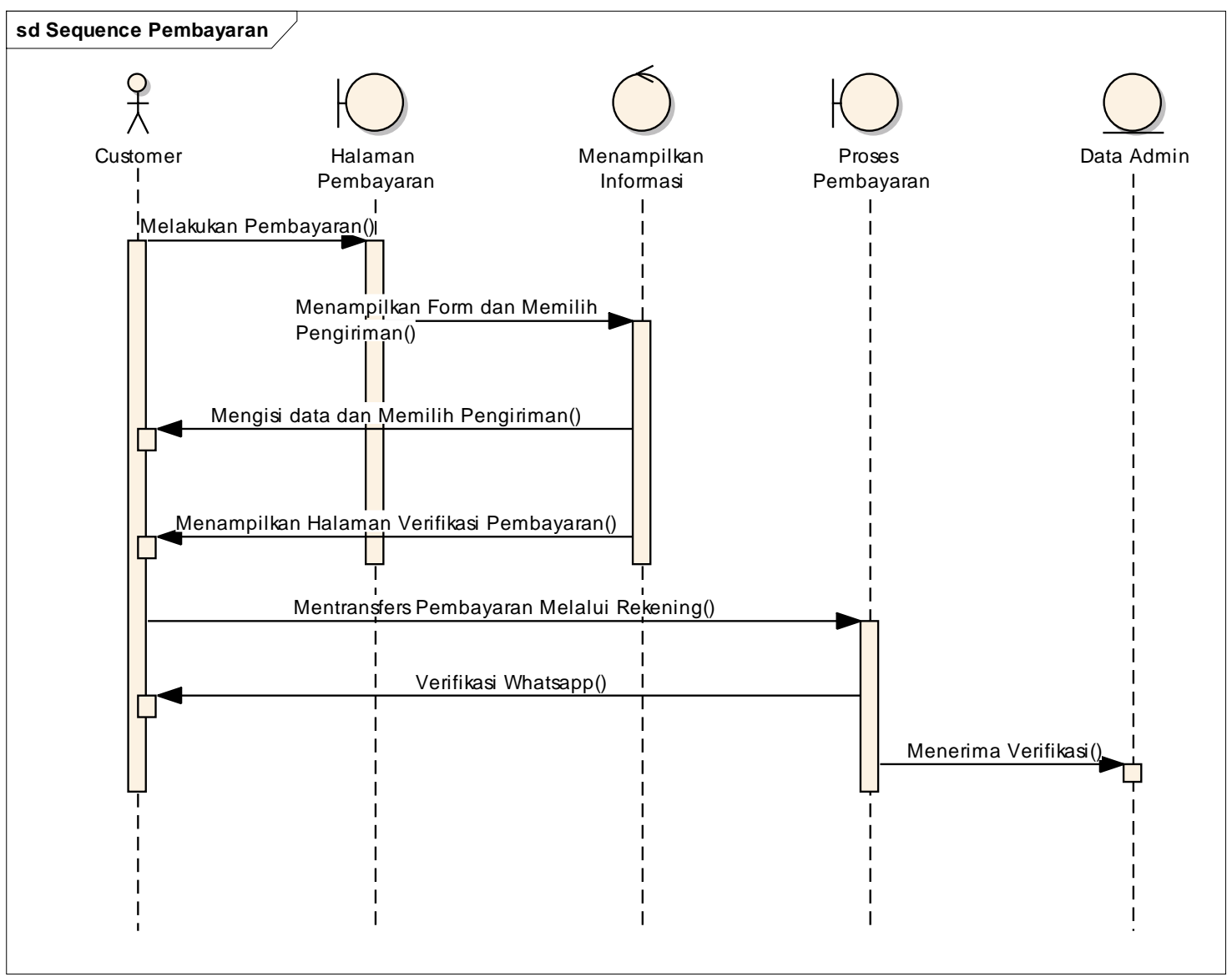

Gambar 7. Sequence Diagram Pembayaran

\subsection{Implementasi}

Tahap ini merupakan kegiatan final dari pembuatan rancangan sistem informasi penjualan online berbasis website dengan menggunakan perangkat lunak maupun perangkat keras. Terdapat beberapa halaman tampilan dalam website Toko Herbal Pahlawan yang akan ditampilkan sebagi berikut:

a. Halaman Login

\section{Login Admin!}

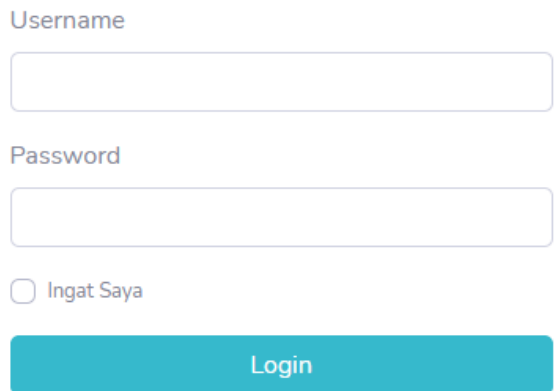

Gambar 8. Tampilan pada Halaman Login 
b. Halaman Utama

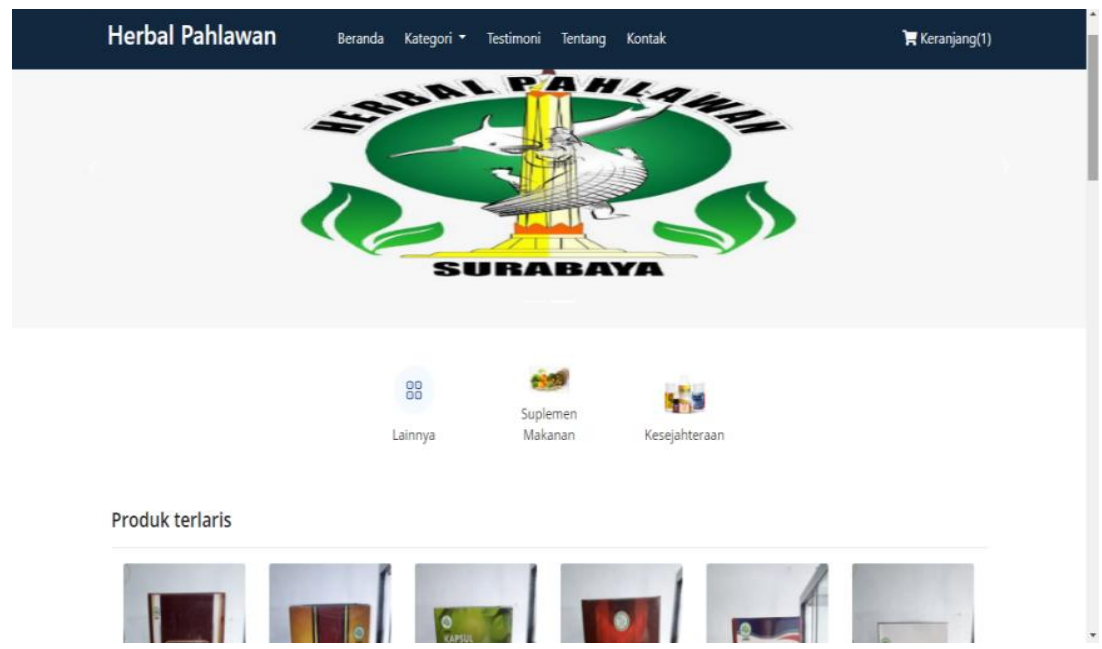

Gambar 9. Tampilan pada Halaman Utama

c. Halaman Dashboard

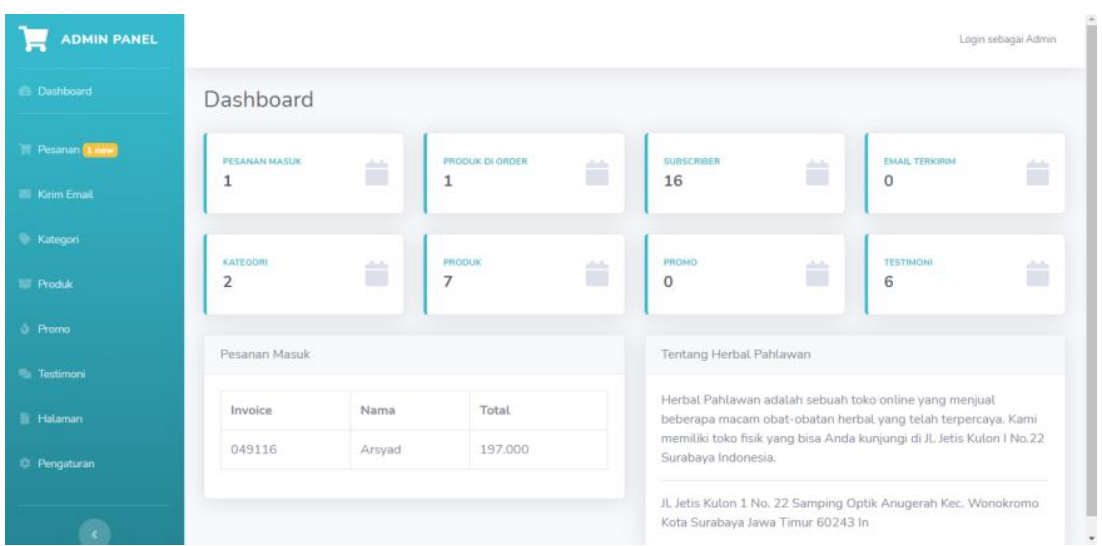

Gambar 10. Tampilan pada Halaman Dashboard

d. Halaman Kategori Produk

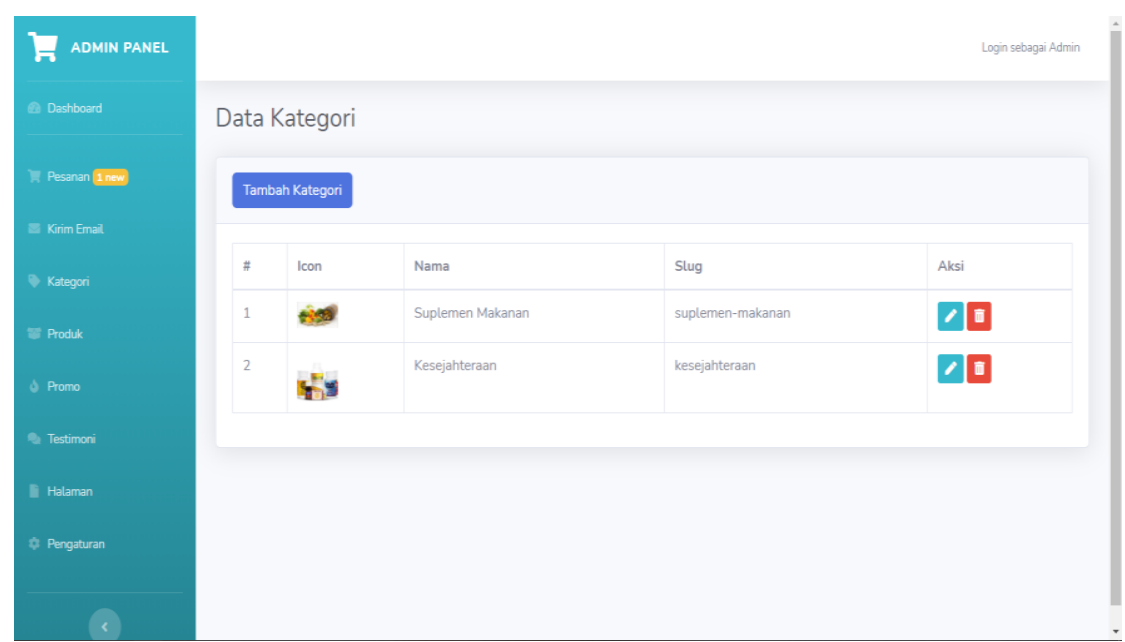

Gambar 11. Tampilan pada Halaman Kategori Produk 
e. Halaman Produk

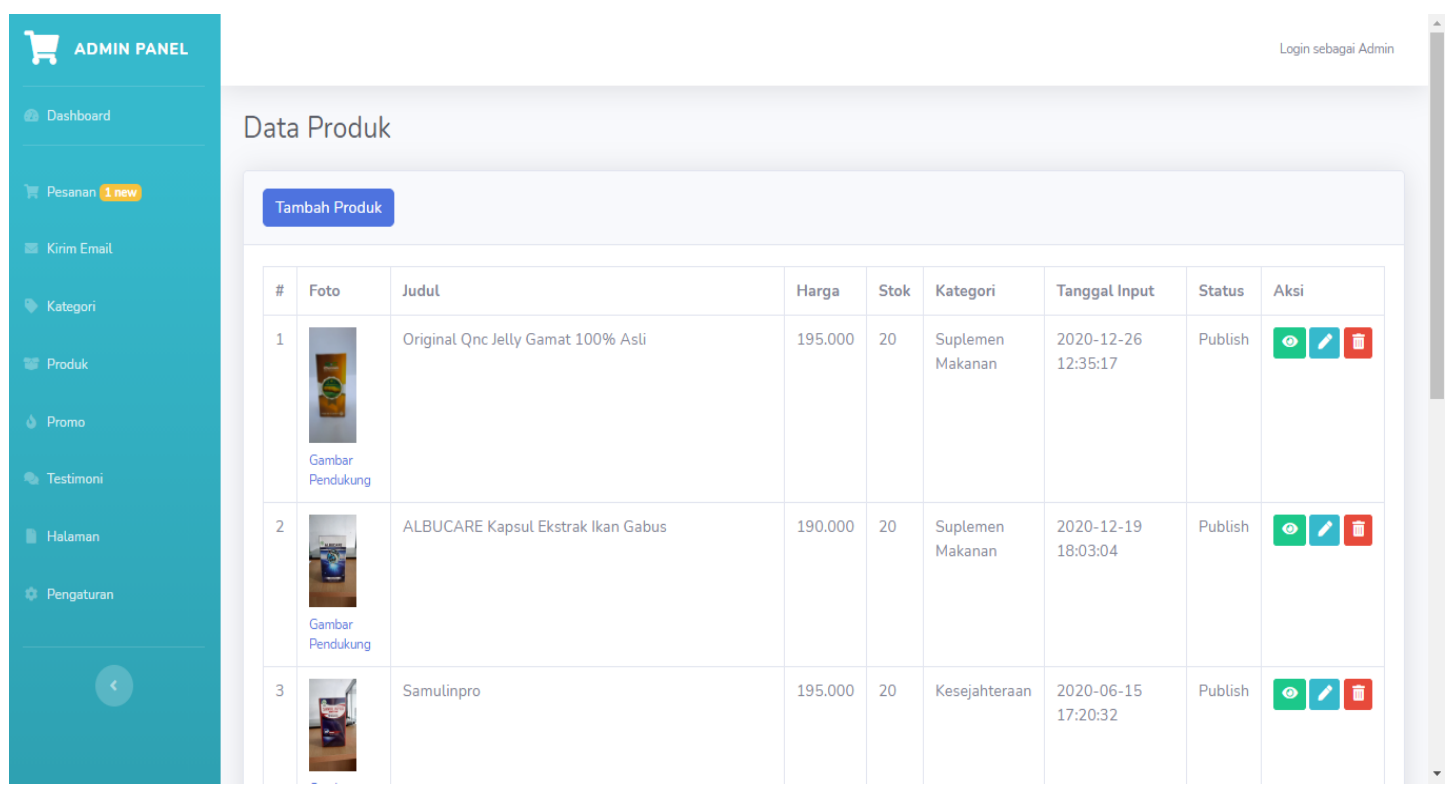

Gambar 12. Tampilan pada Halaman Produk

\subsection{Pengujian Black Box Testing}

Tabel 1. Hasil pada Pengujian Black Box

\begin{tabular}{|c|c|c|}
\hline Aktivasi Pengujian & Realisasi yang diharapkan & Hasil \\
\hline Klik Menu Login & $\begin{array}{l}\text { Muncul tampilan halaman } \\
\text { Dashboard }\end{array}$ & Sukses \\
\hline Klik Menu Beranda & $\begin{array}{lll}\text { Muncul Tampilan Halaman } \\
\text { Beranda }\end{array}$ & Sukses \\
\hline Klik Menu Kategori & $\begin{array}{l}\text { Muncul Tampilan Halaman } \\
\text { Kategori Produk }\end{array}$ & Sukses \\
\hline Klik Menu Testimoni & $\begin{array}{l}\text { Muncul Tampilan Halaman } \\
\text { Testimoni }\end{array}$ & Sukses \\
\hline Klik Menu Tentang & $\begin{array}{lll}\text { Muncul Tampilan Halaman } \\
\text { Tentang }\end{array}$ & Sukses \\
\hline Klik Menu Kontak & $\begin{array}{lll}\text { Muncul Tampilan Halaman } \\
\text { Kontak }\end{array}$ & Sukses \\
\hline Klik Menu Beli & $\begin{array}{l}\text { Muncul Tampilan Halaman } \\
\text { Beli }\end{array}$ & Sukses \\
\hline Klik Menu Tambah Keranjang & $\begin{array}{l}\text { Muncul Tampilan Halaman } \\
\text { Keranjang }\end{array}$ & Sukses \\
\hline Klik Menu Lanjut Pembayaran & $\begin{array}{l}\text { Muncul Tampilan Halaman } \\
\text { Pembayaran }\end{array}$ & Sukses \\
\hline Klik Menu Kosongkan Troli & $\begin{array}{l}\text { Muncul Tampilan Halaman } \mathrm{K} \\
\text { eranjang telah Kosong }\end{array}$ & Sukses \\
\hline Klik Menu Bayar Sekarang & $\begin{array}{l}\text { Muncul Tampilan Halaman } \\
\text { Verifikasi Pembayaran }\end{array}$ & Sukses \\
\hline Klik Menu Klik disini & $\begin{array}{l}\text { Muncul Tampilan Halaman } \\
\text { Konfirmasi } \quad \text { Pembayaran } \\
\text { melalui Whatsapp }\end{array}$ & Sukses \\
\hline
\end{tabular}


Journal of Advances in Information and Industrial Technology (JAIIT), Vol. 3, No. 1

\begin{tabular}{|l|l|c|}
\hline Klik Menu Pesanan & $\begin{array}{l}\text { Muncul Tampilan Halaman } \\
\text { data Pesanan }\end{array}$ & Sukses \\
\hline Klik Menu Kirim Email & Muncul Halaman Email & Sukses \\
\hline
\end{tabular}

Tabel 1. Hasil pada Pengujian Black Box (Lanjutan)

\begin{tabular}{|l|l|l|}
\hline \multicolumn{1}{|c|}{ Aktivasi Pengujian } & \multicolumn{1}{c|}{ Realisasi yang diharapkan } & Hasil \\
\hline Klik menu kategori & Muncul tampilan data kategori & Sukses \\
\hline Klik menu produk & Muncul tampilan data produk & Sukses \\
\hline Klik menu promo & $\begin{array}{l}\text { Muncul tampilan data promo } \\
\text { produk }\end{array}$ & Sukses \\
\hline Klik menu testimoni & Muncul tampilan data testimoni & Sukses \\
\hline Klik menu halaman & Muncul tampilan data halaman & Sukses \\
\hline Klik menu pengaturan & $\begin{array}{l}\text { Muncul tampilan data } \\
\text { pengaturan }\end{array}$ & Sukses \\
\hline Klik menu batal & $\begin{array}{l}\text { Muncul tampilan halaman data } \\
\text { produk }\end{array}$ & Sukses \\
\hline Klik menu pilih file & $\begin{array}{l}\text { Muncul tampilan halaman } \\
\text { manajemen file pada perangkat }\end{array}$ & Sukses \\
\hline $\begin{array}{l}\text { Klik menu unggah } \\
\text { produk }\end{array}$ & $\begin{array}{l}\text { Muncul tampilan halaman } \\
\text { produk }\end{array}$ & $\begin{array}{l}\text { Muncul tampilan halaman data } \\
\text { produk }\end{array}$ \\
\hline Klik menu batal & $\begin{array}{l}\text { Muncul tampilan halaman } \\
\text { manajemen file pada perangkat }\end{array}$ & Sukses \\
\hline Klik menu pilih file & $\begin{array}{l}\text { Muncul tampilan halaman data } \\
\text { produk }\end{array}$ & $\begin{array}{l}\text { Suncul tampilan produk } \\
\text { berhasil dihapus }\end{array}$ \\
\hline Klik menu edit produk \\
\hline $\begin{array}{l}\text { Klik menu "oke" pada ingin menghapus } \\
\text { produk }\end{array}$
\end{tabular}

\section{Kesimpulan (Conclusion)}

Dari hasil pembahasan sistem informasi penjualan online berbasis website pada Toko Herbal Pahlawan dapat ditarik sebuah kesimpulan yaitu, hasil output pengujian sistem menggunakan metode pengujian Black Box adalah menunjukkan hasil sistem secara keseluruhan berhasil (Sukses), hal ini menunjukkan sistem siap digunakan. Sistem Informasi penjualan online berbasis website dapat dijadikan media penjualan oleh Toko Herbal Pahlawan. Serta dapat memberikan keuntungan dalam hal pemasaran dan pelanggan bisa mendapatkan info produk-produknya secara cepat, tepat, dan akurat.

Sistem Informasi penjualan online berbasis website dapat menyimpan data dan laporan penjualan serta memproses penjualan dan pembayaran secara otomatis.

\section{Ucapan Terima Kasih (Acknowledgement)}

Pada kesempatan ini peneliti sangat banyak berterimakasih kepada Bapak Lukman Junaedi selaku pembimbing yang telah banyak memberikan masukan ataupun komentar agar penulisan ini menjadi baik dan rapi. Selain itu peneliti juga berterima kasih kepada Bapak Gustiandi selaku pemilik Toko Herbal Pahlawan yang telah memberikan izin untuk melakukan penelitian ditempat Beliau. 


\section{Daftar Pustaka}

Dharwiyanti, S. And Wahono, R. S. (2003) 'Pengantar Unified Modeling Language (UML)', Ilmukomputer.Com.

Hendini, A. (2016) 'Pemodelan UML Sistem Informasi Monitoring Penjualan Dan Stok Barang', Pemodelan Uml Sistem Informasi Monitoring Penjualan Dan Stok Barang (Studi Kasus: Distro Zhezha Pontianak). Doi: 10.2135/Cropsci1983.0011183x002300020002x.

Hidayat, R., Marlina, S. And Utami, L. D. (2017) 'Perancangan Sistem Informasi Penjualan Barang Handmade Berbasis Website Dengan Metode Waterfall', Simnasiptek 2017.

Indrayani, H. (2012) 'PENERAPAN TEKNOLOGI INFORMASI DALAM PENINGKATAN EFEKTIVITAS, EFISIENSI DAN PRODUKTIVITAS PERUSAHAAN', Jurnal EL-RIYASAH. Doi: 10.24014/Jel.V3i1.664.

Kristanto, A. (2018) Perancang Sistem Informasi (Edisi Revisi), Edisi Revisi.

Pengetahuan, J. I. And Komputer, D. A N. T. (2018) 'Sistem Pendukung Keputusan Penentuan Karyawan Terbaik Menggunakan Metode TOPSIS', 4(1), Pp. 43-48.

Priyambudi, H. (2017) Pengertian Metode Prototype, Tahapan Dan Kelebihan Metode Prototype, 29 November 2017.

Rahmadhani, Y. (2017) 'STRATEGI BRANDING PORTAL ONLINE WWW.TRIPRIAU.COM DALAM MEMBANGUN BRAND AWARENESS SEBAGAI PORTAL ONLINE PARIWISATA PROVINSI RIAU', JOM FISIP.

Rahmawati, N. And Mulyono, H. (2016) 'Analisis Dan Perancangan Sistem Informasi Pemasaran Berbasis Web Pada Toko Billy’, Jurnal Manajemen Sistem Informasi.

Susanti, M. (2016) 'Perancangan Sistem Informasi Akademik Berbasis Web Pada Smk Pasar Minggu Jakarta', Informatika. 